\title{
MOCVD GROWTH OF InP-RELATED MATERIALS USING TBA and TBP
}

\author{
M. CZub and W. StrRupiński
}

Institute of Electronic Materials Technology, Wólczyńska 133, 01-919 Warszawa, Poland

High quality epitaxial layers of GaAs, InP, AlAs, InGaAs, InGaP, In$\mathrm{GaAlP}$ have been grown by low-pressure metalorganic chemical vapor deposition using TMIn, TMGa, TMAl and the less hazardous group V precursors, TBA, TBP. Excellent morphology was obtained for $\mathrm{GaAs}$ and $\operatorname{InP}$ in the temperature ranges of $570-650^{\circ} \mathrm{C}$ and $520-650^{\circ} \mathrm{C}$, respectively. The V/III ratio as low as 1.5 was used to grow epilayers of InP. The $77 \mathrm{~K}$ mobility of InGaAs lattice matched to InP (grown with TBA) was $72360 \mathrm{~cm}^{2} /(\mathrm{Vs}$ ) for $n=1.5 \times 10^{15} / \mathrm{cm}^{-3}$ and a thickness of $2 \mu \mathrm{m}$. Comparable photoluminescence parameters of InGaP between layers grown with TBP and $\mathrm{PH}_{3}$ were achieved, but for InGaAlP (TBP) photoluminescence intensity was signifcantly lower than for InGaAlP $\left(\mathrm{PH}_{3}\right)$. The promising results allow one to apply of TBA and TBP for developing of device structures.

PACS numbers: 68.55.Ce

\section{Introduction}

Tertiarybutylarsine (TBA) and tertiarybutylphosphine (TBP) are being intensively studied for use as alternative to highly hazardous $\mathrm{AsH}_{3}$ and $\mathrm{PH}_{3}$ precursors in metalorganic vapor phase epitaxy (MOVPE). Several orders of magnitude less toxic properties and low vapor pressure of liquid TBA and TBP can contribute to a significant reduction in safety equipment cost and operational constraints. More efficient pyrolysis of TBA ( $50 \%$ decomposed in $425^{\circ} \mathrm{C}$ compared with $575^{\circ} \mathrm{C}$ for $\mathrm{AsH}_{3}$ [1]) and TBP (the pyrolysis is $50 \%$ complete at $450^{\circ} \mathrm{C}$, for $\mathrm{PH}_{3}$ - at $700^{\circ} \mathrm{C}[2]$ ) leads to a better composition control during the growth of quaternary alloys. Moreover, lower TBA and TBP thermal stability comparing with hydrides enables lower temperature growth which is desirable for several reasons, such as suppression of dopant interdiffusion. Many results on MOVPE epilayers growth of GaAs, InP, InGaP, GaInAsP using TBA, TBP precursors have been reported in recent years [3-6]. However, there are a few papers on InGaAlP, a very attractive material for optoelectronics. It is caused by the fact that TBA is now established as an effective source for MOVPE considering the level of residual impurities, thus is acceptable for growth of high-quality GaAs epilayers. However, in the case of TBP using for InGaAlP growth, low deposition temperature enhances a process of aluminum reaction with oxygen [7-9].

In this paper, we present the results on MOVPE growth of III-V materials using TBA and TBP precursors following up the advantages of efficient thermal 
decomposition enabling low temperature deposition. Furthermore, a technological test of impurities concentration in TBP was possible.

\section{Experimental}

The epilayers were grown in horizontal low pressure (20-200 mbar) MOVPE reactor (Aixtron) with IR-heated graphite susceptor. Trimethylindium (TMIn), trimethylgallium (TMGa) and trimethylaluminum (TMAl) were used as III-group sources. The group-V sources were TBA and TBP as well as $\mathrm{AsH}_{3}$ and $\mathrm{PH}_{3}$, for comparison. Bubbler temperatures were kept at $10^{\circ}$ and $17^{\circ} \mathrm{C}$ for TBA and TBP, respectively. The V/III ratio was varied from 0.75 to 80 . All metalorganics were obtained from EpiChem. Pd-purified $\mathrm{H}_{2}$ was the carrier gas with a total flow rate of $6 \mathrm{l} / \mathrm{min}$. The growth temperature was in the range $480^{\circ}-700^{\circ} \mathrm{C}$ depending on the material of epilayer. The substrates were $2^{\prime \prime}$ diameter $n$-type or SI GaAs and InP (100)-oriented and $n$-type GaAs (100)-oriented cut $3^{\circ}$ off towards (110). Before the growth substrates were cleaned, etched and rinsed using de-ionized water. $\mathrm{N}_{2}$-filled glove-box was used for loading to the reactor.

Various type of layers were deposited using TBA, TBP and for comparison, $\mathrm{AsH}_{3}$ and $\mathrm{PH}_{3}$ : GaAs, $\mathrm{Al}_{0.28} \mathrm{Ga}_{0.72} \mathrm{As}$, InP, $\mathrm{In}_{0.53} \mathrm{Ga}_{0.47} \mathrm{As}, \mathrm{In}_{0.49} \mathrm{Ga}_{0.51} \mathrm{P}$ and $\operatorname{In}_{0.49}\left(\mathrm{Ga}_{0.65} \mathrm{Al}_{0.35}\right)_{0.51} \mathrm{P}$. The layers were characterized by means of photoluminescence (PL) in room and helium temperatures, double-crystal X-ray rocking curves, Hall measurements and ion channeling technique. The surface morphology was observed using a differential interference contrast microscope.

\section{Results and discussion}

InP layers were grown using TBP in temperature range from $480^{\circ}$ to $650^{\circ} \mathrm{C}$. It was observed that for a low $\mathrm{V} / \mathrm{III}$ ratio and a low temperature there is a very narrow range of optimal growth parameters that are indispensable for excellent surface morphology, (Fig. 1). In our case the best morphology comparable with InP using $\mathrm{PH}_{3}$ was obtained for a $\mathrm{V} / \mathrm{III}$ ratio and $T_{g}: 1-3,500^{\circ}-535^{\circ} \mathrm{C}$, respectively. Typical electrical parameters measured by the Hall method were $n_{300}=1.5 \times 10^{15} / \mathrm{cm}^{3}$,

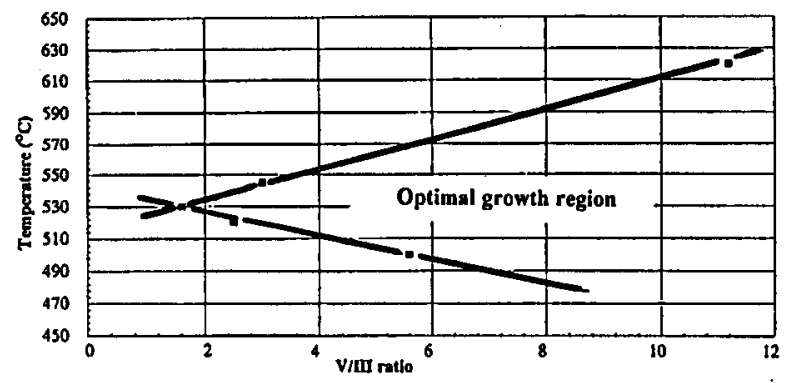

Fig. 1. Optimal growth parameters indispensabled for a mirror-like surface of InP epilayer. 


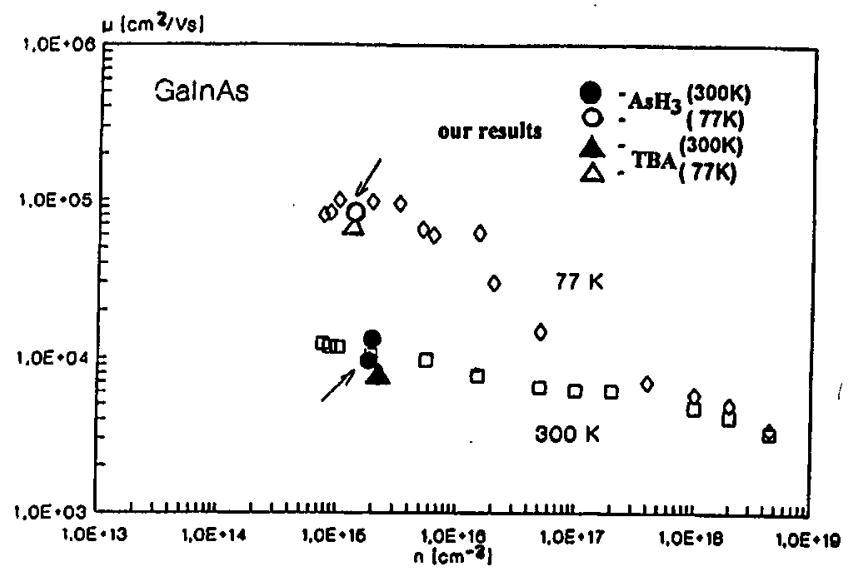

Fig. 2. Electron mobility versus carrier concentration in intentionally doped and unintentionally doped InGaAs layers grown by low-pressure MOCVD [10] in comparison with our results (ITME).

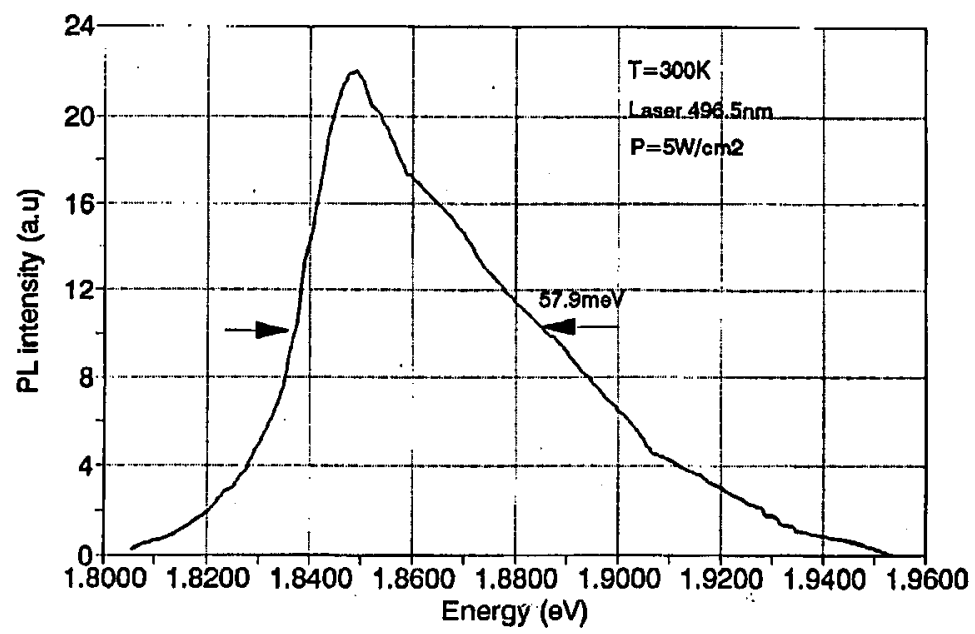

Fig. 3. PL spectrum of InGaP grown at $600^{\circ} \mathrm{C}$ with lattice mismalch $\Delta a / a$ of $5200 \mathrm{ppm}$ and maximum wavelength emission of $672 \mathrm{~nm}$.

$\mu_{300}=3200 \mathrm{~cm}^{2} /(\mathrm{V} \mathrm{s}), n_{77}=1 \times 10^{15} / \mathrm{cm}^{3}, \mu_{77}=35000 \mathrm{~cm}^{2} /(\mathrm{Vs})$ for a thickness of $2 \mu \mathrm{m}$. The major impurities determined by SIMS were S and Si. SIMS results were in good agreement with data from the IIall measurements. The crystal quality of InP-layers grown both using TBP and $\mathrm{PII}_{3}$ were examined by ion channeling method. The difference between InP-layers grown using TBP and $\mathrm{PII}_{3}\left(\chi_{\min }=2.6 \%\right.$ for epilayers and $5 \%$ for substrate) was observed. High quality $\mathrm{In}_{0.53} \mathrm{Ga}_{0.47} \mathrm{As}$ layers were grown at the temperature range $600^{\circ}-650^{\circ} \mathrm{C}$ and for a V/III ratio $=25$. The IIall results were very similar for both cases: InGaAs (TBA) and InGaAs $\left(\mathrm{AsI}_{3}\right): n_{300}=2 \times 10^{15} / \mathrm{cm}^{3}, \mu_{300}=8900 \mathrm{~cm}^{2} /(\mathrm{Vs})$, 
$n_{77}=1.5 \times 10^{15} / \mathrm{cm}^{3}, \mu_{77}=72500 \mathrm{~cm}^{2} /(\mathrm{Vs})$ and $n_{300}=2.2 \times 10^{15} / \mathrm{cm}^{3}$, $\mu_{300}=10400 \mathrm{~cm}^{2} /(\mathrm{V} \mathrm{s}), n_{77}=1.6 \times 10^{15} / \mathrm{cm}^{3}, \mu_{77}=84800 \mathrm{~cm}^{2} /(\mathrm{V} \mathrm{s})$, respectively (Fig. 2). SIMS measurement results indicate $\mathrm{Si}$ as a source of donors.

InGaP and InGaAlP layers lattice matched to GaAs exhibited good surface morphology for minimal $T_{g}$ of $550^{\circ} \mathrm{C}$. For InGaP grown at the temperature of $600^{\circ} \mathrm{C}$ relatively high PL intensity was observed even for lattice mismatched $\Delta a / a$ of $5200 \mathrm{ppm}$. In this case, the wavelength of maximum emission was shifted to $672 \mathrm{~nm}$ (Fig. 3). For InGaAlP a temperature of growth was also $600^{\circ} \mathrm{C}$.

\section{Summary}

The epitaxial layers of binary, ternary and quaternary alloys have been grown at a low temperature and low V/III ratio using TBA and TBP. It was found that for InP-based epilayers the range of optimal growth parameters indispensable for mirror-like surface is rather narrow. The crystal quality and electrical parameters were a little lower in comparison with epilayers grown using $\mathrm{PH}_{3}$. Also, the differences for various bubblers of TBP were observed considering the Hall results which indicates that the purity of TBP determines the quality of layers. The low carrier concentration and the high mobility measured in undoped InGaAs epilayers suggests that the ultra pure level of TBA commercially available was achieved. InGaP and InGaAlP epilayers with a completely mirror-like surface were obtained at the low temperature, however, $T_{g}$ of $600^{\circ} \mathrm{C}$ was the temperature of transition between amorphous and ordered structure.

\section{Acknowledgment}

The authors would like to thank Professor A. Turos and Dr J. Kaczanowski for carrying out the ion channeling measurements. This work was supported in part by grant No.803449101 of the State Committee for Scientific Research (Republic of Poland).

\section{References}

[1] S.P. DenBaars, B.Y. Maa, P.D. Dapkus, A.D. Danner, II.C. Lee, J. Cryst. Growth 77, 188 (1986).

[2] C.H. Chen, C.A. Larsen, G.B. Stringfellow, D.W. Brown, A.J. Robertson, J. Cryst. Growth 77, 11 (1986).

[3] C.A. Larsen, C.II. Chen, M. Kitamura, G.B. Stringfellow, D.W. Brown, A.J. Robertson, Appl. Phys. Lett. 48, 1531 (1986).

[4] S.R. Kurtz, J.M. Olson, A. Kibbler, J. Electron. Maler, 18, 15 (1989).

[5] Y. Takeda, S. Araki, M. Takemi, S. Noda, A. Sasaki, Jpn. J. Appl. Phys. 29, L1040 (1990).

[6] W.J. Duncan, D.M. Baker, M. Harlow, A. English, A.L. Burness, J. Haigh, Electron. Lett. 25, 1603 (1989).

[7] D.S. Cao, G.B. Stringfellow, J. Electron. Mater. 20, 1 (1991).

[8] M. Mannoh, A. Ishibashi, K. Ohnaka, J. Cryst. Growth 145, 158 (1994).

[9] M. Horita, M. Usami, Y. Matsushima, J. Cryst. Growth 145, 291 (1994).

[10] A. Katz, Indium Phosphide and Related Materials: Processing, Technology and Devices, Artech House, Boston, London 1992. 